\title{
Preventing adverse cutaneous reactions from amplified hygiene practices during the COVID-19 pandemic: how dermatologists can help through anticipatory guidance
}

\author{
Margaret A. MacGibeny ${ }^{1}\left[\right.$ Cindy $^{-}$Wassef $^{2}$
}

Received: 17 April 2020 / Accepted: 27 April 2020 / Published online: 9 May 2020

(c) Springer-Verlag GmbH Germany, part of Springer Nature 2020

\begin{abstract}
The COVID-19 pandemic has swept the globe with more than 2,000,000 confirmed cases of SARS-CoV-2 infection in 184 countries and territories. According to the Centers for Disease Control and Prevention (CDC), two crucial actions can reduce the risk of person-to-person viral transmission: frequent hand washing and surface decontamination with specific environmental protection agency (EPA)-registered disinfectants. As hygiene recommendations evolve during the COVID-19 pandemic and community members adopt changing practices, dermatologists are likely to see a rise in adverse cutaneous reactions from prolonged irritant exposures and widespread use of antimicrobials. The purposes of this report are to familiarize dermatologists with the hygiene practices recommended for COVID-19 prevention, to highlight adverse cutaneous reactions associated with repeated exposures to detergents and disinfectants, and to discuss strategies which patients can implement during the COVID-19 pandemic to minimize skin irritation white still performing hygiene practices effectively.
\end{abstract}

Keywords COVID-19 · SARS-CoV-2 $\cdot$ Coronavirus $\cdot$ Irritant contact dermatitis $\cdot$ Allergic contact dermatitis $\cdot$ Hand hygiene $\cdot$ Disinfection

\section{Report}

On March 11, 2020, COVID-19 was declared a pandemic by the World Health Organization (WHO). The SARS-CoV-2 infection has swept the globe with 2,101,164 confirmed cases and 140,773 deaths in 184 countries and territories as of April 16, 2020 [4]. According to the centers for disease control and prevention (CDC), two crucial actions can reduce the risk of viral transmission: frequent hand washing and surface decontamination. While such amplified hygiene measures are of utmost importance for the prevention of person-to-person viral transmission, these changes in practice are projected to trigger a rise in adverse cutaneous reactions such as contact dermatitis in the community. Dermatologists

Margaret A. MacGibeny

macgibma@rwjms.rutgers.edu

1 Rutgers Robert Wood Johnson Medical School, 675 Hoes Ln W, Piscataway, NJ 08854, USA

2 Department of Dermatology, Rutgers Robert Wood Johnson Medical School, 1 World's Fair Dr, Ste 2400, Somerset, NJ 08873, USA should be familiar with the hygiene practices recommended for COVID-19 prevention and prepared to counsel patients on strategies to combat potentially debilitating skin damage that can result from repeated exposure to detergents and disinfectants. In this report, we review the recommended hygiene procedures for prevention of emerging viral pathogen transmission and discuss the adverse skin reactions associated with these augmented hygiene practices. We conclude with strategies which patients can implement during the COVID-19 pandemic to minimize skin irritation white still performing hygiene practices effectively.

In response to the SARS-CoV-2 outbreak, the CDC and environmental protection agency (EPA) released updated guidelines for infection prevention. The CDC describes proper hand hygiene as frequent hand washing with soap and warm or cool water for $20 \mathrm{~s}$ or use of alcohol-based hand sanitizers with at least 60\% alcohol [2]. For disinfection of environmental surfaces, the EPA released emerging viral pathogen recommendations for the use of antimicrobial pesticides against SARS-CoV-2 [9]. Although limited data are available regarding survival of SARS-CoV-2 on surfaces, early reports suggest that viable virus can be detected on certain materials like stainless steel or plastic for up to 48 or 
$72 \mathrm{~h}$ following viral exposure, respectively [10]. Disinfectants meeting the EPA criteria for use against SARS-CoV-2 contain active ingredients such as quaternary ammonium, sodium hypochlorite, peroxyacetic acid, hydrogen peroxide, and alcohols, many of which are known skin irritants or allergens [11, 12].

As hygiene recommendations evolve during the COVID19 pandemic and community members adopt changing practices, dermatologists are likely to see a rise in adverse cutaneous reactions from prolonged irritant exposures and widespread use of antimicrobials. Adverse consequences of frequent hand hygiene include skin dryness, irritant contact dermatitis, and allergic contact dermatitis [12]. Skin dryness is an early sign of damage to the natural skin barrier, which can result from recurrent use of lipid-emulsifying detergents that deplete lipids in the stratum corneum. Lipid-dissolving alcohols in hand sanitizers may also contribute to barrier dysfunction [6]. Following barrier compromise, irritants and allergens can more easily breach the stratum corneum causing inflammation in the deeper layers of the epidermis and contact dermatitis. Dermatitis symptoms include dryness, roughness, itching, burning, erythema, edema, blistering, scaling, and fissuring. The most common form of contact dermatitis is irritant contact dermatitis from direct exposure to environmental irritants. While strong irritants like caustic chemicals may induce acute dermatitis on initial contact, milder irritants like hot water, detergents, or alcohols may require multiple exposures to cause skin damage. Recently, a high incidence of hand hygiene-induced skin damage was reported in first-line COVID-19 healthcare workers at the epicenter in China. Of 434 healthcare workers in Hubei province, $74 \%$ (321) performed hand hygiene more than ten times per day, and $76.6 \%$ (246) of these frequent washers reported hand skin damage with dermatitis symptoms [7]. A less common form of contact dermatitis is allergic contact dermatitis, which can occur when patients have hypersensitivity reactions to fragrances, preservatives, or chemical antimicrobials in detergents or disinfectants [12]. Among the 370 EPA-registered disinfectants for SARS-CoV-2 (as of April 16, 2020), the most common active ingredient is quaternary ammonium, found in 203 of the registered products [9]. Importantly, the quaternary ammonium salt, quaternium-15, was found to be the allergen most frequently associated with a positive patch test reaction (16.5\%) in a study of 959 patients with allergic contact dermatitis of the hands [11].

To combat adverse cutaneous reactions from shifting hygiene practices, skin moisturization and allergen avoidance are paramount throughout the COVID-19 pandemic. Regular use of oil-containing emollients after hand washing has been associated with reduced skin damage [5]. In a double-blind, randomized trial of healthcare workers with occupation-associated severe hand irritation, scheduled use of oil-containing lotion was superior to barrier cream for improvement of hand skin scaling, cracking, and pain [8]. Subjects treated with oil-containing lotion also exhibited a $50 \%$ increase in the mean total number of hand washes per day by the fourth week of use, suggesting that improved skin condition correlates with increased hand hygiene compliance. In addition to preventive skin moisturization, precautions should be taken to avoid contact with allergens in surface disinfectants. Patients should always wear gloves and clean hands upon completion of product use.

Dermatologists can promote protective strategies throughout the COVID-19 pandemic by endorsing the following CDC- and EPA-based recommendations related to hand hygiene and surface disinfection: First, proper hand washing procedures entail wetting hands, lathering with soap, scrubbing for at least $20 \mathrm{~s}$, rinsing with clean running warm or cool water, and drying hands. Hot water was not shown to significantly improve hand washing efficacy, and patients should avoid washing hands with hot water to minimize skin damage [3]. Second, antibacterial soaps should be avoided, because they were not shown to be superior to non-antibacterial cleansers at preventing infectious illness symptoms in community, non-healthcare settings [1]. Avoidance of antibacterial chemicals in soaps may reduce patient risk of irritant or allergic skin reactions. Third, if soap and water are not available, alcohol-based hand sanitizer (at least $60 \%$ alcohol) can be rubbed into hands for 20 s. Patients can reduce their risk of allergic skin reactions by avoiding fragrance-containing sanitizers. Fourth, surfaces should be disinfected with EPA-registered products for use against hard-to-kill emerging pathogens. The active ingredients have predicted efficacy against SARS-CoV-2 but are also known skin allergens, so patients should avoid direct skin contact with these disinfectants by wearing impermeable gloves during use and cleaning hands on completion. Finally, emollient moisturizers should be applied regularly after hand washing to combat barrier damage induced by irritant or allergen exposure. Use of skin moisturizers may promote long-term hand hygiene compliance, thereby decreasing the risk of pathogen transmission over time. By providing anticipatory guidance to patients during the COVID-19 pandemic, dermatologists can help to limit the adverse cutaneous effects associated with evolving hygiene practices in the community setting.

\section{Compliance with ethical standards}

Conflicts of interest Margaret A. MacGibeny and Cindy Wassef declare that they have no conflicts of interest.

Ethical approval Not applicable. 


\section{References}

1. Aiello AE, Coulborn RM, Perez V, Larson EL (2008) Effect of hand hygiene on infectious disease risk in the community setting: a meta-analysis. Am J Public Health 98(8):1372-1381. https://doi. org/10.2105/AJPH.2007.124610

2. Centers for disease control and prevention (2020) Coronavirus disease 2019 (COVID-2019). How to protect yourself \& others. https://www.cdc.gov/coronavirus/2019-ncov/prepare/preve ntion.html

3. Jensen DA, Macinga DR, Shumaker DJ, Bellino R, Arbogast JW, Schaffner DW (2017) Quantifying the effects of water temperature, soap volume, lather time, and antimicrobial soap as variables in the removal of Escherichia coli ATCC 11229 from hands. J Food Prot 80(6):1022-1031. https://doi.org/10.4315/0362-028X. JFP-16-370

4. Johns hopkins university coronavirus resource center (2020) COVID-19 Dashboard by the center for systems science and engineering. https://coronavirus.jhu.edu/map.html

5. Kampf G, Ennen J (2006) Regular use of a hand cream can attenuate skin dryness and roughness caused by frequent hand washing. BMC Dermatol 6:1-6. https://doi.org/10.1186/1471-5945-6-1

6. Kownatzki E (2003) Hand hygiene and skin health. J Hosp Infect 55(4):239-245. https://doi.org/10.1016/j.jhin.2003.08.018

7. Lan J, Song Z, Miao X, Li H, Li Y, Dong L, Yang J, An X, Zhang Y, Yang L, Zhou N, Yang L, Li J, Cao J, Wang J, Tao J (2020) Skin damage among health care workers managing coronavirus disease-2019. J Am Acad Dermatol 82(5):1215-1216. https://doi. org/10.1016/j.jaad.2020.03.014
8. McCormick RD, Buchman TL, Maki DG (2000) Double-blind, randomized trial of scheduled use of a novel barrier cream and an oil-containing lotion for protecting the hands of health care workers. Am J Infect Control 28(4):302-310. https://doi.org/10.1067/ mic. 2000.107425

9. United States environmental protection agency (2020) List N: disinfectants for use against SARS-CoV-2. https://www.epa.gov/ pesticide-registration/list-n-disinfectants-use-against-sars-cov-2

10. van Doremalen N, Bushmaker T, Morris DH, Holbrook MG, Gamble A, Williamson BN, Tamin A, Harcourt JL, Thornburg NJ, Gerber SI, Lloyd-Smith JO, de Wit E, Munster VJ (2020) Aerosol and surface stability of SARS-CoV-2 as compared with SARS-CoV-1. N Engl J Med 382(16):1564-1567. https://doi. org/10.1056/NEJMc2004973

11. Warshaw EM, Ahmed RL, Belsito DV, DeLeo VA, Fowler JF, Maibach HI, Marks JG, Toby Mathias CG, Pratt MD, Rietschel RL, Sasseville D, Storrs FJ, Taylor JS, Zug KA (2007) Contact dermatitis of the hands: cross-sectional analyses of North American contact dermatitis group data, 1994-2004. J Am Acad Dermatol 57(2):301-314. https://doi.org/10.1016/j.jaad.2007.04.016

12. World Health Organization (2009) WHO guidelines on hand hygiene in health care: first global patient safety challenge clean care is safer care (p. 61-65). https://www.ncbi.nlm.nih.gov/books /NBK144013/pdf/Bookshelf_NBK144013.pdf

Publisher's Note Springer Nature remains neutral with regard to jurisdictional claims in published maps and institutional affiliations. 